\title{
Assessment of Implementation of Energy Efficiency Measures, Savings Achieved and Barriers to Implementation at Various Firms in the Hospitality Industry in Kenya
}

\author{
Anne Kariuki, Ernest Odhiambo
}

\begin{abstract}
The approval of the Energy Act 2006 in Kenya was followed with energy audits and efficiency campaigns, collaboration by different institutions and specialized training driven using various platforms. The energy audits help in the identification of conservation opportunities. Since 2006, over 1,000 energy audits have been performed. Efforts have been made to advance the management of the energy agenda in addition to establishing an enabling and effective environment through legislation. These methods include energy efficiency campaigns like the replacement of inefficient bulbs with LEDs that targeted more than a million households by the national utility company Kenya Power through its Demand Side Management department. The study adopted a descriptive research design and targeted hotels and restaurants within Nairobi. Primary data was collected by means of a semi structured questionnaire. The same unit is in-charge of ensuring that consumers use the energy they have efficiently by readily offering information. According to the Energy Regulations 2012, Energy audits are compulsory for facilities that have an annual consumption above 180,001 $\mathrm{kWh}$. The sector is regulated by the Energy Regulatory Commission (ERC) which issues licenses through a rigorous process to individuals and firms who have qualified to conduct energy audits within the designated facilities. Learning institutions have also started coming up with specialized training to assist in capacity building of individuals within the sector. Several certification courses which are recognized in the country and internationally have been embraced by the regulating body and the experts in the fraternity. This review paper aimed at investigating the implementation of measures of energy efficiency, savings attained and the challenges faces in different organizations within the hospitality sector in Kenya. The paper aimed at solving the problem of energy efficiency measures in the hospitality sector since there are no proper placed policies managing the energy sector in Kenya.
\end{abstract}

Keywords: Energy Efficiency, Implementation, Barriers, Hospitality Industry and Measures.

\section{INTRODUCTION}

Manuscript received on February 05, 2021.

Revised Manuscript received on March 03, 2021.

Manuscript published on April 30, 2021.

* Correspondence Author

Anne Kariuki*, Energy Management, Department of Mechanical Engineering, School of Engineering, University of Nairobi, Kenya.

Ernest Odhiambo, Thermo-Fluids Lecturer, Department of Mechanical Engineering, School of Engineering, University of Nairobi, P.O. Box 30197-00100, Nairobi, Kenya.

(C) The Authors. Published by Blue Eyes Intelligence Engineering and Sciences Publication (BEIESP). This is an open access article under the CC BY-NC-ND license (http://creativecommons.org/licenses/by-nc-nd/4.0/)
Energy management and efficiency has in the recent past been the highlight of both industrial and domestic setups. Kenya's energy generation mix has been heavily dependent on hydro power which is vastly affected by the weather. The cyclical drought brings with it a drastic reduction on power available for the grid system. This led to power rationing in early 2000 that also affected the country's already struggling economy. Renewable energy generation is an expensive and long term endeavor who's benefits may not be felt immediately upon implementation. The other alternative was for the government to have thermal power plants on standby that are faster to start whenever needed. The downside of the plants is that they are more expensive to run and have an adverse effect on the environment considering that the key drivers are petroleum products as shown in Figure 1.1.

Current Power Capacity in Kenya
\begin{tabular}{|l|c|c|}
\hline $\begin{array}{l}\text { Sources } \\
\text { (MW) }\end{array}$ & $\begin{array}{c}\text { Installed Capacity } \\
\text { (MW) }\end{array}$ & $\begin{array}{c}\text { Capacity } \\
\% \text { Share }\end{array}$ \\
\hline Hydro & 763.3 & $50 \%$ \\
\hline Thermal & 527.5 & $34 \%$ \\
\hline Geothermal & 198 & $13 \%$ \\
\hline Cogeneration & 26 & $2 \%$ \\
\hline Wind & 5.45 & $0.4 \%$ \\
\hline Isolated grid & 14.6 & $1 \%$ \\
\hline Total & 1,529 & $100 \%$ \\
\hline
\end{tabular}

Figure 1.1: Power capacity in Kenya

The focus will mainly be on industries that have undertaken the energy audit and implemented the EE (Energy Efficiency) and RE (Renewable Energy) measures as recommended. Energy audits assist firms to identify opportunities for energy conservation. It is hoped that firms will implement the identified energy conservation measures and benefit from the resultant energy and financial savings in addition to other national benefits such as Carbon Dioxide $\left(\mathrm{CO}_{2}\right)$ emission reductions.

\section{MOTIVATION}

The demand for energy is on the rise across the world as industrialization is expanding rapidly. This has resulted in the energy crises and the increase in depleted energy resources al over the world.

\section{Published By:}

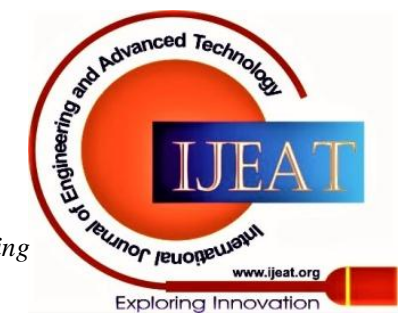




\section{Assessment of Implementation of Energy Efficiency Measures, Savings Achieved and Barriers to Implementation at Various Firms in the Hospitality Industry in Kenya}

Most developing countries have not implemented fully the energy efficiency measures due to lack of policies managing the energy sector. Buildings in the European Union use $40 \%$ of the total energy and $36 \%$ of $\mathrm{CO}_{2}$ gas is emitted. By 2035 , it is forecasted that in the UK, the emission of fossil fuels from households and consumption of electricity will grow by $11 \%$ in comparison to the levels recorded in 2015 . Energy efficiency is adopted as a policy target with the aim of reducing the level of $\mathrm{CO}_{2}$ emissions. Hence, it is not a wonder that buildings that uphold the principle of energy efficiency are central to energy and environmental programs.Notably, the improvement in energy efficiency does not automatically result in decarbonization unless the energy is emitted from fossil fuels. Contrary to this, the influence of energy emitted from sources that are low in carbon is weak. It is apparent that the link between energy efficiency measures (EEMs) and sustainability, thus, it is crucial to educate the public on the importance of energy efficient buildings for social and private benefits.

Essentially, the improvement of energy efficiency in buildings provides an opportunity to lower the levels of emissions, thus lowering the costs. It is worth noting that this opportunity is yet to be tapped due to the high upfront financing and long payback time periods. In general, in transitioning and developing nations where the construction sector is growing rapidly and at a significant rate, the main priority is to ensure that the new buildings adhere to the set standards of energy efficiency.

In Kenya, the Energy Bill, 2015 espouses that the Energy Regulatory Authority (ERA) has the responsibility to facilitate, establish and implement the management $f$ national energy and programmes related to conservation (GoK, 2015). The ERC (2018) explains that the implementation of the energy efficiency has been poor in Kenya. The responsibility of the ERA helps the authority to undertake energy audits so as to be in a better position to offer the best advice to consumers of electrical energy. The users of the energy also need to develop plans on energy investments, measures of conservations and report implementation failures from which the fine ought to be not less than 250,000 or a imprisonment term of not less than 9 months.

Due to the high demand of energy from various sectors in the country and low supply of power, energy efficiency is essential in the country, therefore this study aims at establishing the implementation of EEM, attained savings and challenges faced within the hospitality industry in Kenya.

\section{Energy Efficiency and Renewable Energy Resources}

Ottinger (2017) assessed the laws on EE and renewable energy resources with respect to the UNEP and drew the conclusion that renewable energy and EE has great potential in generating safer, secure, economic and cleaner energy in the future. In developing states, these renewable resources offer an opportunity to move past the traditional sources of energy without endangering the environment. However, it was observed that some of these renewable technologies are not competitive in terms of cost. In addition, there exists many challenges in terms of the transfer of the technology, its financing and pricing, required infrastructure and the training and education needed that have to be addressed before the clean resources are universally adapted. Regardless, these sources of energy are fast growing as is exhibited in Figure 1.2 below.

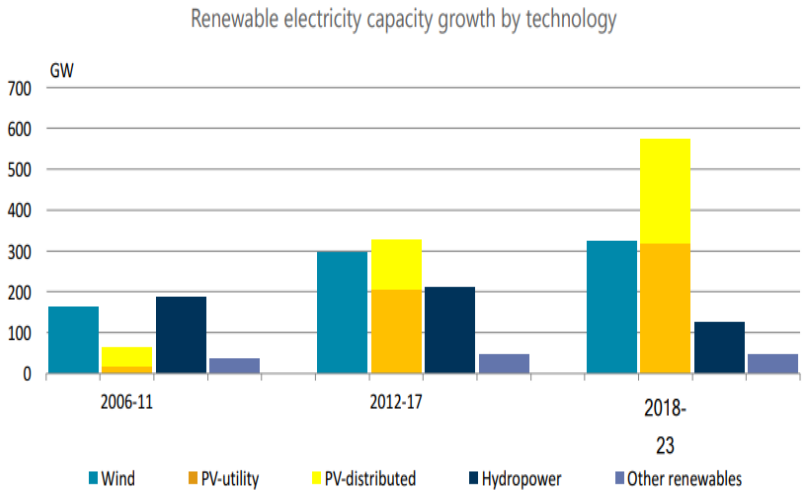

Figure 1.2: Renewable electricity capacity growth in Kenya

Worrell, E. (2014), did a research on the challenges faced in the implementation of EE and found that deterrence in the end usage of energy is refered as the mechanisms and forces that can be adopted in specific markets in a way that inhibits the investments and behaviour that can increase the usage of EE. In terms of classical economies, failures in the market take place when these challenges are revealed to hinder actions that increase economic and energy efficiency. In the contents of the study, is a barrier is identified to deter cost effective investments in an economic framework, it is perceived to be a failure of the market. An evaluation on the policies that promote the reduction of greenhouse gas emmissions was undertaken by Ürge-Vorsatz and Mirasgedis (2017) and reasoned that the commercial and private buildings account roughly $33 \%$ of all energy related emissions of $\mathrm{CO}_{2}$ around the world, which is required to increase in the years to come. A wide range of challenges, for example, failures of the market, hidden expenses and benefits, uptake-costs challenges, structural, behavioral and informative challenges deter the actualization of the regularly determined significant saving potential. These hindrances can be tended to by different policy instruments Notwithstanding, as there exists different policy instruments, picking the suitable instruments requires an intensive evaluation of these tools and the significant comprehension of the local circumstance similar to the policy environment. Nkosi and Pretorius (2017) examined the barriers and strengths of existing EE management practices in Steam Industries and reasoned that the steam sector over the course of the years have put forth groundbreaking attempts to redesign the management of energy efficiency in South Africa; by creating policies and initiating EE systems and educational programs. Regardless, a broad efficiency gap actually remains in the sector of power generation and the rationale behind is that, government's endeavors to create energy efficiency has been pointed towards commercial and residential industries of the economy.

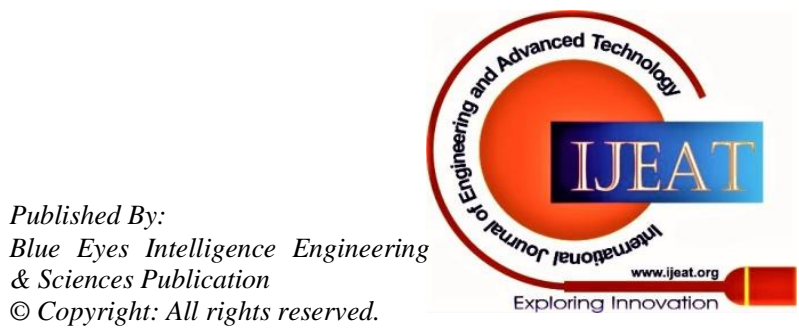


The evaluation on anaerobic digester energy generation: opportunities and barriers was undertaken by Karekezi, Kithyoma and Onguru (2016) The study indicated that the identification of the constraints has already been made, and steps have been put in place to offer solution. However, it is clear that time will be needed for the fruition of the set steps. As indicated, the implementation delays will negatively affect poor states such as Uganda and the costs of adaptation will be higher at a later date. Efforts need to be put in the implementation of $\mathrm{EE}$ and renewable energy. The government alone cannot undertake these tasks - the government needs the participation and support of other stakeholders including multilateral and bilateral financing institutions. Stiebert (2014), in his study Kenya's Climate Change Action Plan concluded that the Kenyan government has put in place a National Energy Strategy. In order to attain its 2030 vision of becoming a middle-income state, Kenya must address the challenges on lack of adequate supply of power and weak electricity networks. Over the next years, investments in capacity generation and in strengthening the electricity network will still be lagging behind to be at per with the expected demand of electricity from household and economic activities.

Brent (2016) conducted a study to promoting the use of renewable energy and EE. The author recommended that towns and cities must offer solutions to the many challenges and hindrances to facilitate the establishment of modern energy systems. The appropriate policy response relies on the local circumstances, that included the economic, social and environmental goals; the size and density of the population, the market structure, capital availability, the available expertise, energy mix and existing infrastructure. According to Rhosenberg and Winkler (2014) energy efficiency needs to be perceived as more than the management of the demand of electricity. In energy efficiency management as a resource, fossil fuel, renewable energy and nuclear energy consumption and usage must be considered. It was also observed that policy on EE does not follow a homogenous pattern and can vary from state to state and in particular between developing and industrializes states. Therefore, global best practices need to be established to the state conditions to facilitate effective implementation. In specific circumstances, this may demand re-strategizing the government role and developing new structures of institutions.

The research on the energy end-use efficiency of industrial energy efficiency improvement, Fawkes, Oung Thorpe, Zhu and Farrell (2016), concluded that using the resources of EE by improving the energy efficiency of industries is a sane reaction for all nations to energy-related issues. Such issues incorporate the need to advance energy security and to decrease negative environmental effects at global and local levels. The advantages of advanced EE are enjoyed by everyone: the ventures making the advancement, to the energy supply system, and to the whole economy. These advantages are: scaled down costs of energy and reduced exposure to the volatility of energy costs, efficiency can bring numerous other non-energy advantages like improved employee engagement and productivity, creation of jobs and improved wellbeing with fewer health expenses. On the yearly energy loss in the Kenyan hospitality sector the information showed a variation on energy loss was recorded throughout the previous ten years, with the year 2012 showcasing the greatest loss while 2019 account the least energy loss as indicated in figure 1.3 below

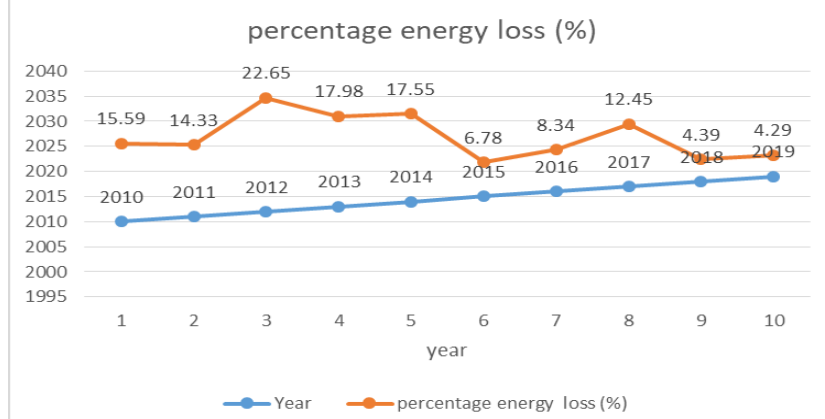

Figure 1.3: Percentage annual energy loss in hospitality industry in Kenya

\section{Energy Savings Mechanisms}

Cingoski and Petrevska (2018), targeting hotels found that hotels consumed a lot of energy , water and other nondurable items, in this way inciting considerable environmental effects. Then again, they depend on clean nature and unpolluted climate as a fundamental core value for the hotel industry. Regularly, tourists forsake the travel destinations in poor environmental conditions and look for lodgings with ecolabel, eco endorsement and an authentication for EE. They are completely mindful of various ecological concerns the travel industry improvement is confronting, so they have moved their accommodations preferences towards eco-accommodating lodging establishments by favoring green items and showing an ability to pay for 'green' services. Contemporary tourists anticipate that an environmentally responsible hotel should live up to their ecological requirements and desires. This incites a significant adjustment in the hotel business, which has consistently perceived the need for getting greener in order to be positioned competitively. Subsequently, the hotel business is getting progressively environmentally responsible by dealing with EE. The yearly energy consumption within the hospitality sector has been on the ascent for the most recent decade as demonstrated by figure 1.4

\section{average annual energy consumption in hospitality industry in kenya}

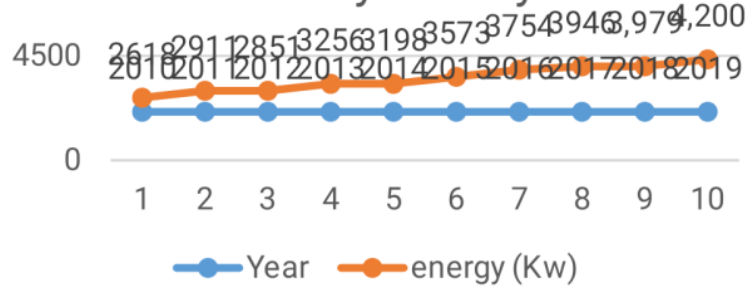

Figure 1.4: Annual energy consumption in hospitality industry in Kenya
Published By:

Blue Eyes Intelligence Engineering \& Sciences Publication

(C) Copyright: All rights reserved.

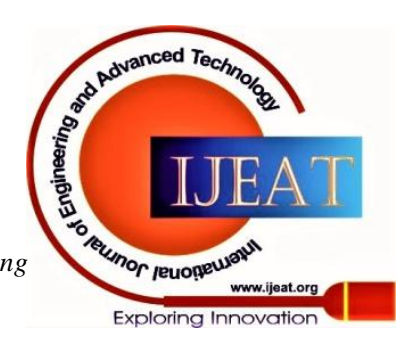




\section{Assessment of Implementation of Energy Efficiency Measures, Savings Achieved and Barriers to Implementation at Various Firms in the Hospitality Industry in Kenya}

A study by Sarkar and Singh (2014) on accelerating energy efficiency concluded that the Africa's geographical scale tries to engage with other impractical states. The study recommended that states need to engage with organizations at the regional level and in particular fro East Africa, West Africa, Southern Africa and North Africa. Establishing regional energy efficiency (EE) hub in these respective regions can facilitate easy information sharing and the establishment of necessary plans of action for efficiency. In addition, the interaction of the hubs can exist. Williams (2014) undertook a research on EE focusing on the buildings industry from the Hyderabad experience and found that the challenges of efficiency can result in the owners of the buildings not enjoying the cash flow benefits of improvement of efficiency and thus cannot specify the efficiencies. Inadequate demand results in inadequate supply of services and products to promote the establishment of green buildings. In addition, it leads to increased prices whenever the products are not available within the local market. Inadequate supply hinders designers from specifically identifying efficient services and products. Programs on market and information facilitation such as labels are not in high demand since there exists no differences in the energy efficiency to distinguish. In the same way financial institutions ignore energy cost differences since they are deemed to be uncommon and small while the labels are not easily available.

Schleich (2017), noted that the electric EE and combined natural gas programs can offer more energy and cost savings that contribute to greater customer service and satisfaction. These benefits have been shown to be achievable on a large scale, through a variety of institutional structures, in residential, business, and institutional customer segments, in multiple states showing leadership in energy efficiency policy (Nowak Kushler and Witte, 2014). As utilities and other administrators attain high cost-effective energy savings levels, greater program integration and inter-utility cooperation represent a significant opportunity. The barriers to further development of combined programs are admittedly numerous. In the main, they are institutional and organizational. They are not issues that are solved once and stay solved. Participating gas and electric utility program managers must continuously engage and cooperate to ensure that new patterns of inter-utility cooperation become the norm. Schleich (2017), also study on the EE economics, challenges on investments, and it was revealed that the contextual investigation results introduced in this paper for the higher education sector in Germany affirm the idea that there are challenges to EE. That is, there are components that repress the selection of beneficial EEM. The principle obstruction discovered were different types of split impetuses.Then again, on opening the EE opportunity, Scheer Durusut and Foster (2015), noticed that examination gave a definite investigation of the scope of measures which could add to the objective and the assortment of policy interventions which could guarantee the objective is met in the most cost-effective way imaginable. For the public, commercial, residential industry and street transport areas, all key EEM have been distinguished. Through a mix of bottom up stock modelling and situation improvement, appraisals of the specialized energy saving potential of each measure have been inferred. The lifetime expenses of the energy reserve funds related with each measure have then been determined by fusing cost information. This study goes past a gauge of the specialized and economic saving potential by consolidating the conduct and dynamic cycle of buyers. A consumer model of the process of decision making has been created to gauge the take-up of EEM under an assortment of policy intercessions. The model has been made up with informational collections on decision making of the consumer accumulated through unique hands on work and through an examination of existing information. This was practically like Schleich (2014), who upheld the view that challenges help to clarify the absence of investment in energy-efficiency technologies, it is past its scope, nonetheless, to survey whether these obstructions ought to be solved since they hinder monetary efficiency. For instance, the expenses for introducing meters might be restrictively high in sub-sectors with low energy costs. Further, from the viewpoint of neoclassical economics, poor access to capital may be a challenge, however it need not suggest a capital market failure that ought to be adjusted.

\section{Energy Efficiency Policies and Programs}

A study on metropolitan effectiveness, a worldwide research of building energy efficiency policies in urban areas was conducted byTakagi, Sprigings, Nishida, Graham and Horie Lawrence (2015). The report featured different building EE policies in urban communities around the globe and intends to fill in as a resource for city authorities as they configure new building EE policies or audit existing ones. Its particular aims are to represent the scope of various policies, reports about the vital conditions, challenges and opportunities of such policies, and assess the approaches that were successful and the reasons behind their success. Also, Poulsen and Sornn-Friese, (2015), did an investigation on attaining EE ship operations under third-party administration, how management models in ships impact EE? They reasoned that the EE gap in ship operations is genuine. There are cost effective measures to lower fuel utilization in the operations of ships explicitly with regards to the planning and execution of voyage, management of power and monitoring of performance, however they are rarely embraced.

The investigation has featured how particularly behavioural perspectives, including measurements of limited rationality and the human perspective, create challenges to EE pf operations in a ship. Determining, focusing on, executing and surveying measures of operational fuel saving and incorporating best practice for EE ship operations is a tedious cycle, which can require years King and Perry (2017), indicated that new programs of EE that incorporate smart technologies particularly exhaustive programs, rather than single-framework retrofits or singlemeasure could help increase the deployment of smart buildings.

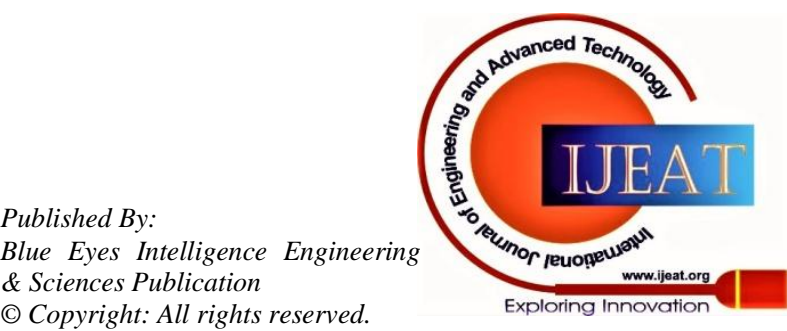


King and Perry (2017), observed that responsibility from trade partners and manufacturers to offer training could likewise promote the awareness and understanding of the technologies and help solve the issue of poor preparation by building operators.

Incentive programs should target small and medium buildings to expand the take-up of smart technologies. This could profit proprietors of single buildings who come up short on the forthright funding to make such investments, just as tenants who need to lower their energy bills by introducing a single measure, like a smart thermostat. Martinaitis, Kazakevičius and Vitkauskas (2017), concluded that improvements in EE that are genuine and cost effective 'no second thoughts' measures the individual consumer and producer concerned saves costs and the local area profits by diminished contamination, including the abatement of greenhouse gas emissions. There is no uncertainty that such chances exist. Yet, the potential for making such enhancements, and the extension for governments to productively intercede to address obstructions and hindrances forestalling their take-up, seems, by all accounts, to be unassuming. By and large, the upgrades are not as cost effective for a single producer and customers as they would appear, when the entirety of the expenses are taken into consideration. What's more, not many of the many hindrances and obstructions are zones where government intercession is legitimized. Experiential study on EE policies and trends in the tertiaty and household sectors revealed that the achievement factors and the inspiration for the EEM in buildings were examined, Schlomann, Eichhammer, Frölich and Tariq (2015), on the grounds that numerous barriers have been identified in their usage. The inspiration for this investigation came from the way that more pragmatic examinations, and documentation of them, are important to raise the level of trust in the EEM. The investigation was performed by assessment, monitoring and verification of the energy savings incited by actualizing EEM. The building data set of 41 structures was created in a nonexclusive manner, so it was easy to make comparisons of the results. The building dataset included: inns, schools, places of business, shopping centers, sports and health centers. Dubey and Dodonov (2019), too did an examination on planning of existing EE standards and innovations in structures and suggested that States should set out the essential measures in building guidelines to guarantee that the materials and items utilized in development are dependent upon thorough quality control cycles to meet the prerequisites for EE while keeping up combustion performance, seismic opposition, and fire guaranteeing they do not threaten the safety of property and people. Experimentally study on the private sector energy efficiency programme by Cagno and Trianni, (2014) concluded that the program has prevailed in its central goal to, through strong working associations with business, constructing a superior, more effective and energysecure and safe future for South Africa. Although, the program reached a conclusion in 2015, the great work done by its numerous members will proceed and stretch out to different organizations. Cagno and Trianni, (2014) focusing on SMEs observed that particular EEM in compressed air systems regularly face data related obstructions, like absence of data on advantages and costs in regards to the thought about measure. In any case, regardless of whether the audit uncovered not many non-energy benefits, their reality is still significant since these may lead to the solution to the hindrances over the long haul, improving EE. A real examination on significant obstructions to usage of EE projects in Bulgarian was undertaken by Rezessy, Dimitrov, Urge-Vorsatz and Baruch, (2016). It was observed that each EE project needs a standard to have the option to quantify and confirm the savings. No precise specialized and monetary defense of the project can be inferred without a record of its past energy costs for a delegate and adequately extensive stretch of time. There are no cutting-edge metering gadgets to peruse the provided and additionally devoured energy and energy carriers. Notwithstanding a lack of metering gadgets, energy information is restricted because of poor upkeep of logbooks that track standard operations. Working staff are regularly low-skilled and under compensated. Nair Gustavsson and Mahapatra (2014) found that roughly $55 \%$ of the administrators of cooperative housing associations have a positive attitude towards reducing the use of heat. The lower issue towards power use by the respondents could be on the grounds that the family power bill is normally metered independently and the aggregate burden of power cost is less. Nonetheless, larger part of co-operative housing association does not mean to change/replace majority of their buiding envelope segments during the following ten years. One reason is that the associations were happy with the state of existing building envelop segments. In the present circumstance, it is imperative to build the consciousness of EE alternatives. Many respondents didn't know about the different EE prospects in building envelope The DOE (2014) found that reviews/audits improve EE since they raise awareness of potential upgrades. The acknowledgment of $\mathrm{EE}$ gains however essentially relies upon a successful subsequent activity. Cattaneo, (2019), did an exploration too on internal and outside hindrances to EE feedback is a viable method to impact conduct associated with energy use, specifically if the input is joined with an objective intervention. Feedback that offers peer examination on energy use drives energy conservation. There are other social impact, for example, interventions where the data is given by block pioneers that end up being successful on the grounds that they convey the feedback less secretly. The feedback medium can also impact conduct, with feedback that utilizes the most captivating and intelligent medium (like a PC) being the best.

This opens up to the likelihood that further advancement of IT applications, online media, and phone messaging will guarantee larger enhancements in EE later on. Likewise, Sorrell (2014) on hindrances to EE, proof from chosen sectors O'Malley Scott and inferred that there are many opportunities that are cost effective and accessible in the vast majority of the associations concerned. A larger part of interviewees in every one of the areas concurred that there were numerous EE opportunities accessible in their associations that would have very short recompense periods.

\section{Published By:}

Blue Eyes Intelligence Engineering
\& Sciences Publication

(C) Copyright: All rights reserved.

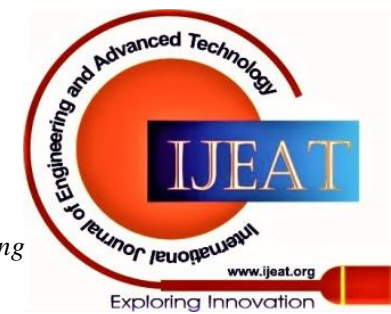




\section{Assessment of Implementation of Energy Efficiency Measures, Savings Achieved and Barriers to Implementation at Various Firms in the Hospitality Industry in Kenya}

This proposes that there would be significantly more freedoms that would have a preferable pace of return over the expense of capital. Examination on the hindrances to modern EE and found that there is some overlap among obstructions and the connected effective models and openings across the three kinds of mechanical EE Sardianou (2018). By and large a solitary activity, or gathering of activities,

can address different hindrances. Vogel Lundqvist and Arias (2015) Categorized the challenges of EE in building and established a framework that relied on their structural origins as to have a clear understanding of the source of these challenges in the Swedish building sector. Through the implementation of the proposed framework on the challenges faced on EE is obvious that the areas of issue in the building sector are not associated wo any structural level; out of the 38 identified challenges, 18 have their own contextual level; 11 originate from the sector level; ,and another 11 originate from the project level. This implies that that majority of the areas deterring change in buildings origin at hierarchy levels that cannot be reached by actors in single building projects after the start of the projects. In addition, the largest areas of the challenge originate from the contextual level, followed by the hierarchy level which is harder to affect the owner/developer of the building. Hindrances towards the EE improvements and a onechallenge-one- measure approach needs to be avoided. Reddy (2015) explained that each challenge may be composed of other sub-challenges. According to Trianni and Pugleise (2014), having a clear understanding of the challenges facing EE is essential for institution and future policies. Available taxonomies on the challenges do not identify all of the aspects identified in extant literature. Hence, a novel methodology has been proposed whose aim is to include all the essential contributions in the topic.

A policy framework for business energy efficiency and concluded that different sectors and sub-sectors have different salience drivers and will therefore react best to different sets of measures. However the UK's experience with the suggestion that the alternative "one size fits all" approach is inadequate except for the most universal measures like taxation and energy pricing, also Semboja (2014), concluded that quantification of energy savings potential was not possible in four out of the five pumping installations studied because of lack of installed metering equipment. More energy efficiency information can be obtained if portable metering equipment can be used in collecting data.An investigation on the front line of Green Growth Sustainability in Kenya was undertaken by Muthuki, (2016) and found that over the years, the Center for Energy Efficiency and Conservation has been on the cutting edge of green development and sustainability in the country. The ventures we will keep on co ducting will add to increasing investment and initiatives in policy framework that advance Green Economy in the country. The point is to improve and uphold the current and future public projects on the production of clean and sustainable energy, climate change and to keep on advancing EE, conservation and management. Similarly Mutua and Kimuyu (2015) did a research on the conservation of household energy in Kenya, assessing the motivators and potential savings and inferred that hypothetically, energy conservation is driven by numerous components, including the longing to decrease cost/price, ecological issues, management of energy demand, state awareness to conserve energy, regulatory objectives and other demographic determinants, for example, household head gender, educational achievement and status of employment of the household head, and in general the energy consumption of a household. In spite of the fact that there are numerous approaches that can be utilized to assess energy conservation, the situation was kept straightforward by embracing discrete decision and ordinary least squares models to odds of conservation and the energy savings levels contingent on specific fuels of conservation. An examination on policy choices to solve hindrances to industrial EE in developing states by Mallett and Sorrell (2014), presumed that any efforts to make a product standard requires monetary investigation and political will, and technical issues, for example, a local testing lab. Any such lab would almost certainly require the utilization of innovation from somewhere else, just as a budget plan and startup financing. Empirical research on expulsion of hindrances to EE and energy conservation in SMEs uncovered that the network of EE evaluators has not been adequately established. Follow-on exercises to set up this, including legislation stimuli ought to be created. Ndichu, Blohmke Kemp, Adeoti and Obayelu (2015), did an examination on the reception of EEM by institutions in Africa and found that the commitment of policy to advancement appropriation is feeble. The environmental guideline was a driving element for $2.5 \%$ of the organizations, and government motivating forces were a driving factor only for $2.5 \%$ of the organizations interviewed. The most significant driving policy factor for maize mill operators in Kenya was energy regulatory requirements. Lah (2015) indicated that decreasing emissions of greenhouse gases in the transport industry is a challenge. Progress in the sector is different from state to state, yet it is evident, as investigated in this paper, that policies are the fundamental component that can clarify these distinctions. The packaging and integration of policies is an essential component of the (relative) successes. Also, Mukwaya and Okidi-Lating (2014) did an investigation on the baselines of energy performance and the designation and benchmarks of institutional, industrial and commercial users of energy in Kenya and presumed that the benchmarks assumption is that usage of energy will increase linearly with a relative increase in any of the metrics of comparison. After the underlying benchmarks were determined, a portion of the benchmark ranges for some, sub-areas were bigger than anticipated, which demonstrated that a few institutions in the sub-regions may have utilized a few thousand times more energy for each measurement than others. Investigative study on energy efficiency strategy MlamboNgcuka (2015) and the study revealed that Government must be able to measure the efficiency and effectiveness of the implemented measures and initiatives undertaken to promote EE as highlighted in the Energy policy.

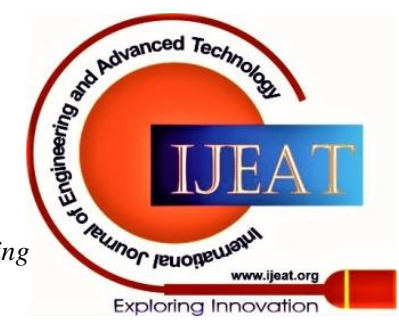


MoEP (2016) recommended that Kenya's current policy for energy efficiency in the power sector is ambitious and ubiquitous, although the main challenge is to fulfil implementation by the electricity users. However, a few additional measures can be suggested based on the present study. Similarly, a study investigating the situational analysis of the energy industry, its policy and strategy for Kenya was carried out by Owiro, Poquillon, Njonjo and Oduor (2015) The authors concluded that making investments in reliable new technologies, research and modern infrastructure increases the efficiency and capacity and drives the adoption of clean energy, as well, McCollum,Wilson, Pettifor Ramea and Fujisawa (2017), did a research on integrated analysis of the energy policy focusing on household and transport energy industries and indicated that given the outcomes of the analysis, efforts need to be made to develop recommendations for policies that solve the negative social, economic and environmental impacts as well as improving the positive impacts. Gachuri (2017), noted that there has been a major stride towards energy efficiency by manufacturing companies. All of the companies interviewed are considered one of the leading manufacturing companies in their sectors and are considered high energy intensive companies in Kenya. They have all undertaken an energy audit as per the Energy Management Regulation of 2012 and have already begun implementing their energy audit report recommendations. World Health Organization. (2018) did an investigation on the transition opportunities to safe and clean energy in the household revealed that the inter-ministerial groups require support. Kasae (2014) revealed that the progress in EEM adaption by manufacturing companies has facilitated cost savings. The findings of the research also suggested that there is need for increased awareness by all stakeholders including the government on EE usage by manufacturing companies. UNEP (2017) did an investigation on addressing the challenges of $\mathrm{EE}$ and indicated that the financial environment does not favor the EE investments. Efforts by financial agencies to finance EE projects remains relatively low in many countries of the world, including developed countries and countries with economies in transition in the region A study on renewable energy incentives in Kenya by Boampong and Phillips (2016) found that the global energy models also help to clarify the kinds of policy measures that would be needed to reach the three sustainable energy objectives. Ockwell and Byrne (2016), did an investigation on sustainable energy for Innovation, technology and propoor green transformations and concluded that Kenya is endowed with diverse energy sources including biomass, hydro, geothermal, solar and wind power, coal and oil, much of which is untapped. To increase per capita electricity consumption and expand electricity access, the GoK is encouraging investment in generation capacity, distribution systems and in developing indigenous sources of energy. Moreover, scope exists for accelerating electrification to meet growing demand, especially in the rural areas through off -grid solutions as indicated by figure 1.5 below.

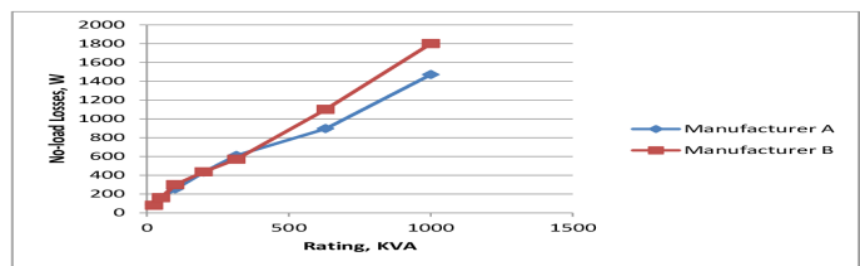

Figure 1.5: Energy efficiency by manufacturing firms in Kenya

An investigative research on realizing energy management practices as a competitive strategy among manufacturing firms in Kenya Yatich (2018) and the finding showed that manufacturing firms have various options to contribute to the ERC membership so as to gain a competitive advantage with most of the respondents having a positive preference. Hence ERC membership should be a consideration in attaining competitive advantage. Also Henry Chepkilot, Kalio and Koima, (2014) did a study on re-thinking energy efficient technology in sustaining competitive advantage among manufacturers in developing economies and the results showed that household location, fuel prices, household head characteristics (gender, education level and type of employment), property rights over dwellings, perception of cleanliness and affordability, and awareness of fuel conservation regulations are all key determinants of the likelihood of conserving energy and the consequential savings in monetary terms.A study on Household energy conservation in Kenya, estimating the drivers and possible savings and the results Mutua and Kimuyu (2015), indicated that energy prices can be utilized to motivate energy conservation and sustainability. The efficacy of changing prices as the policy tools vary from one type of household energy to the other but especially, efficacious for kerosene and wood. wood and kerosene. Mörtberg, Kalantari, Kordas Deal and Cvetkovic (2017), analyzed the Kenyan energy policy while focusing on energy consumption within the transport and household sector. The findings indicated that energy planning experiences challenges in the country. The gaps identified included a process that is not systemic, inadequate consultation with stakeholders consultation, lack of continuity in representation, inadequate integration of social and environmental issues, inadequate and weak systems of data.

\section{Implementation of Energy Efficient Measures}

According to Meath, (2017), EEMs implementation at all levels of demand/supply chain can significantly lower the associated negative effects on human well-being and the environment and increase the availability of energy reserves while enjoying maximum benefits with regards to the output of energy. The consumers and suppliers' costs can be reduced while at the same time ensuring the energydependent initiatives are maintained at the same level.

Munene, Odongo, and Nyambane (2019), observed that different aspects of consumption and demand for energy that affect the practice of energy efficiency in Kenya. Education and socio-economic class were identified as the central determinants in the practice of energy efficiency in different households.

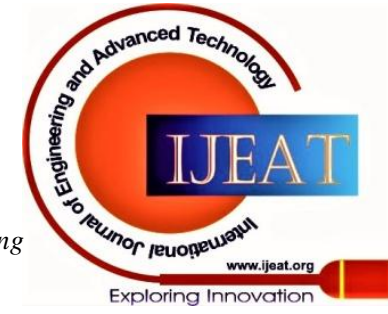




\section{Assessment of Implementation of Energy Efficiency Measures, Savings Achieved and Barriers to Implementation at Various Firms in the Hospitality Industry in Kenya}

Moreover, its was identified that the determinants also influenced the choice of sources of information and energy. The study indicated that the financial capacity of some Kenyans allowed them to adapt energy efficiency practices while others did not. Other determinants that were identified included the appliances and energy cost, attitude of the user, and the access to information on energy efficiency and energy conservation.

On the same note a research on the potential opportunities

and challenges in the execution of energy efficiency in pumping installations in Kenya by Simiyu (2018) found that tackling all these opportunities will lead to improved energy efficiency of the systems. However a number of obstacles and barriers existed in these installations that had made it difficult to realize the energy saving opportunities. One of

the problems encountered in all the five installations is inadequate technology knowledge of the parameters of performance of the pumping systems. Second was the poor information available on efficient equipment. Third is the institution policy and structure of management have not prioritized EE. Company management's are more concerned on the output of the product that the concumed energy and its cost, thus EEM is not prioritized. Gachau (2017), as well did a study on the identification of opportunities of energy saving in commercial buildings in Equatorial Fidelity Centre in Westlands Nairobi. Five major areas were identified that would potentially lower energy bill in EFC namely; Use of Light pipes in the basement to supplement artificial lighting, Use of Roof top Solar PV for Lighting load, replacement of existing Fluorescent tube with LEDs, Power factor Improvement and Tariff Migration. All these measures were found to contribute in lowering energy consumption and hence lowering energy bill. Annual cost saving was found to be Kshs.4,010,663.93 with a payback period of 3 years and 1 month. Kidere (2017), assessed EE at the Kenya Ports Authority and revealed that the Mombasa port energy profile, was unmistakably clear that achievement in EE attempts requires the utilization of both operational and technical measures, managed from an enabling structure. The current measures for $\mathrm{EE}$ at the port, along with progressing movement to "Green Port Policy" set a basis for the accomplishment of energy objectives. Substantially more can be accomplished from the consolidated utilization of the estimates assessed in this study and alternative fuels. The KPA's structure is at present ill-equipped to necessitate the Green Port Policy. The Port additionally doesn't have the mandate, executive directive, financing and resources to viably work an ecological change and in creating and executing the Green Port activities at the Port. Golove and Eto (2016), also in their examination found that the market hindrances to EE is a basic reappraisal of the reasoning for public policies to advance EE. Little of this data has been communicated officially utilizing the market failure and/or transaction const conceptual framework. We recommend that further examination and explanation of existing outcomes according to these ideas is essential for establishing future EE public policies in these markets. We have attempted to integrate a portion of the gray writing in these terms. Much information has been shared, however in many areas a debate still exists. Now and again, we have had the option to recognize regions where these speculations can, on a basic level, be settled by future examinations.
On the other hand, Al-Qawasmi, Abokhalil, Daoud, and Abu-Isbeih, (2018), noted that energy utilization in various seasons and distinctive hours of the day. Specifically, the proposed approach had the option to accomplish a monthly energy saving of $23 \%$ for lighting, auxiliary sources, cooling, warming and electric equipment. Meshcheryakova (2017), additionally did an exploration on the implementation of measures of energy saving in households and inferred that the main hindrance to the utilization of energy service contract (ESC) instrument in Russia is the absence of long-term financing for designing organizations and energy service institutions. Energy service is another system by which banks are unfamiliar and under which they are not set up to give ESC loans at this stage secured exclusively by the financing generated at the institutions by saving resources. In small and medium engineering institutions no capacity to draw in task financing or longhaul credit due to the high evaluation of credit risk of such institutions by banks and the pertinent requirements of the latter to offer liquidity support as shown in Figure 1.6.

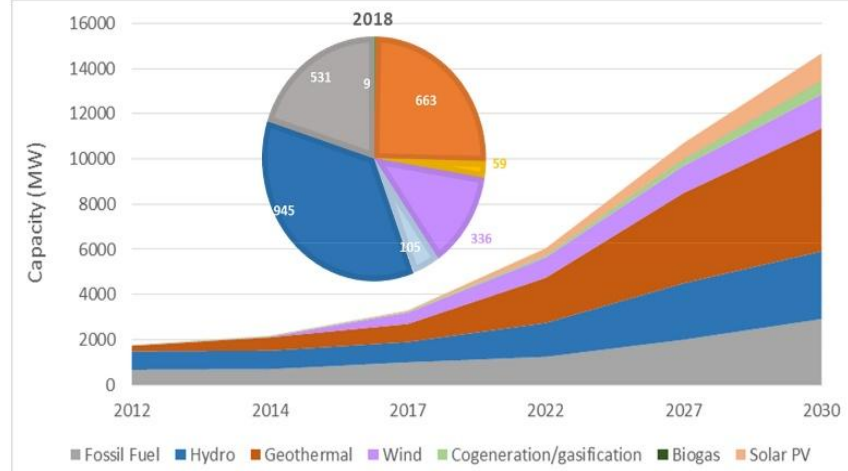

Figure 1.6: Installed electricity capacity (MW) in Kenya in 2018 and national targets for the energy mix in power generation until 2030

A research by Reddy (2014), on an emerging taxonomical approach revealed that at the policy level, some of the hindrances can barely be affected by an EE project team and if individuals encounter these challenges they have to address them. However, in case the project is wide in scope it has the ability to modify some of the challenges it faces. Thus, it is essential to identify the challenges that are easily changed and those that are difficult to change, a key concern to be tackled in such programs. This can assist both the government and multilateral agencies in devising new strategies so as to support the removal of barriers in future programs. The analysis has great implications for the challenges taxonomy which facilitates EE projects.

The study documents the importance of classification and identification of genuine challenges which are preconditions for effective EE technologies diffusion. An investigative study by Ayyappan, Raghavan, Poonthalir, Srinivas and Babu (2019) on unlocking national energy efficiency potential and recommended that there needs to be efforts in identifying demand side resources as alternative options of resources in the energy resource basket of electric utilities. Two options are broadly available for policy makers to attain this.

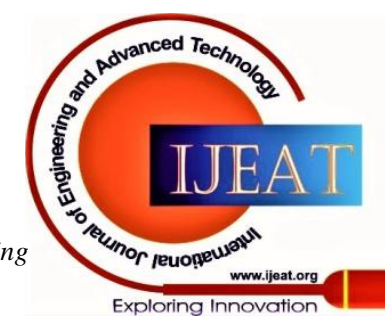


In the first option the demand side resource can be viewed as independent resources apart form the renewable and conventional sources of energy.however, this will require action of a legislative nature to empower the regulatory commissions of state for effective consideration and enforcement of DSM by the utilities and government. In the second option, the demand side resource is identified as a qualifying resource. Also Xu, Pengp and Chan (2015), did a research on the Barriers to Implementing Energy Performance Contracting (EPC) and concluded that solutions are needed to address such challenges. These solutions include; offering education programs, demonstration and information programs, offer adequate training, establish an accreditation system, establish operating standards and provide policy incentives. The outcomes of the research were based on hotel buildings. The conclusion drawn was that EPC mechanism implementation in other projects of energy efficiency ought to be undertaken in future studies. The investigation study on Kenya's Power Sector 2015-2020 Africa, (2015), concluded that collaboration with top management stakeholders within the Kenyan energy sector on energy efficiency recommendations assist the industry in attaining its overall objectives. Other efforts are being undertaken, hence the investigation highlights the gaps identified in the sector through deep diagnosis. Retallack, Johnson Brunert, Rasoulinezhad and Taghizadeh-Hesary (2018), in their investigations on energy efficiency finance programs, assessed a number of financing programs for energy efficiency. The outcomes indicated identified some challenges categories namely commitment and awareness, expertise and technical solutions and financial resources. There is a possibility that aligning the most common solutions have emerged from programs of EE and case studies that have identified these challenges categories.

In his research on the barriers to energy efficiency, Giner-Reichl (2015), concluded that the barriers in increasing EE include change resistance, high costs, uptake costs, implementation of energy reviews/audits suggestions, expense incurred in establishing energy standards, poor technical expertise and poor infrastructure. The opportunities identified of increasing the practice of EE included raising awareness on EE projects, gaining support from private partners and sectors and prioritizing environmental issues. Council, W. E. (2016), the paper; Energy efficiency policies around the world, recommended that introducing and strengthening policies on energy efficiency is essential and sustainable efforts are needed for long-term goals. To ensure effective programs of energy efficiency, the programs must be grounded on developing appropriate strategies and techniques.

On raising the standards of energy efficiency, McKerracher (2015), concluded that the advantages of the energy efficiency promote the growth of the economy and help in reducing climate change incidents, however, there are challenges faced to attain this potential. To address such challenges there is a need for international cooperation that supports the standards of energy efficiencies. According to Figuerora (2016) in his research on the uptake of efficient lighting among the urban poor in the informal residential areas of Kenya, there is a lilnk between the consumption of informal electricity and usage and WTP for efficient lighting in Kibera, Nairobi. The flat rate payment of electricity, usage of incandescent bulb to generate heat, perceptions associated with CFL and the durability of incandescent bulb and views on lighting technologies were found to have a significant influence on the usage of CFL. On the side of supply, quality assurance can largely contribute towards building the confidence of the customers in the efficient lighting goods such as the LEDs and the CFLs. Quality testing can facilitate in addressing the real and expected challenges that can deter uptake by the market. Energy intensive sectors including the steel, aluminum and steel industries have invested resources to increase energy efficiency. In other sectors, energy costs accounts for $10 \%$ or less in the budget, thus not a priority in such industries.

The investigation on sustainable Energy Solutions in East Africa Szabo, Bódis, Huld and Moner-Girona (2014), concluded that there is a need to conduct long-term training on renewable energy so as to establish a critical mass of trained manpower with the necessary technical, sociocultural and economic skills required to increase the use of alternative renewable sources of energy. Koskimäki (2014), similarly on his paper on Development of Energy Efficiency in Sub-Saharan African Cities recommended that despite the energy-saving potential in these sectors, any EE (Energy Efficiency) initiative would fall under the mandate of the national government. Also, initiatives identified in these sectors are more likely to be rolled out on a larger scale, including a number of cities, rather than localized.The study on overcoming barriers to sustainable implementation by Zeng, Tian and Tam (2017), and they recommended that undertaking remediation operations needs proper planning and evaluation considering all constraints. The book content provides necessary information to facilitate remediation implementation while putting into consideration all the stages. Also Kariuki, D. (2018) on his paper on Barriers to Renewable Energy Technologies Development had a discussion that clarified that many factors challenge renewable energy technologies adoption and development. Starting with the progressive use of coal which implies that people are still reluctant to consume alternative sources of renewable energy. Other factors include sociocultural issues, governance, politics, environmental and technical issues. Iwaro and Mwasha reviewed energy conservation policy and building energy regulation and found that building energy regulation is important in reducing the consumption of energy in a building.

Besides, it us used widely as an instrument in majority of developing states with the aim of controlling a building's energy consumption. However, the state of developing nations with regards to the implementation of energy regulation towards energy efficiency and consumption is yet to be identified. An investigative study on the household consumer role in adapting the use of renewable energy technologies in Kenya by Kiprop, Matsui and Maundu (2019) assessed the perceptions of household residents in Kenya on supplies of renewable energy.

Published By:

Blue Eyes Intelligence Engineering

Retrieval Number: 100.1/ijeat.C22260210321

DOI:10.35940/ijeat.C2226.0410421

Journal Website: www.ijeat.org
\& Sciences Publication

(C) Copyright: All rights reserved.

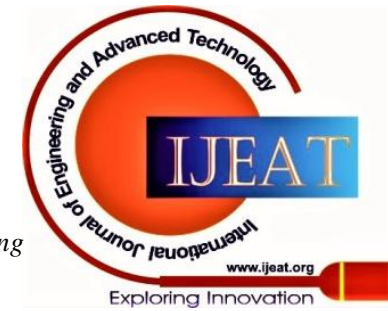




\section{Assessment of Implementation of Energy Efficiency Measures, Savings Achieved and Barriers to Implementation at Various Firms in the Hospitality Industry in Kenya}

The study also assessed the factors motivating and challenging the renewable energy technologies adaption in 3 regions in Kenya as shown in Figure 1.7. Schleich (2014), on his paper on Barrier busting in energy efficiency in industry he concluded that from a national point of view, enhancing EE may result in the improvement of energy supply security, lead to increased productivity and employment and end energy poverty.

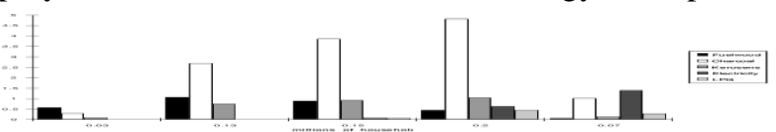

Figure 1.7: Kenyan urban household energy consumption

An empirical study on decision-making barriers in energy transition discovered one hindrance that holds organizations back from executing EEMs are feeble government procedures, (Yazdanpanah \& Ardestani, 2015). The organizations commented that irregularities in government policies, absence of infrastructure to help developments related to energy efficiency, and the shortfall of motivators curb organizations settled outside the Netherlands to put resources into these measures. Moreover, Zhu and Zalesny (2014),

did a study on Energy Efficiency Technologies the investigation of potential of energy efficiency showed that considering the assumption - the accompanying outcomes for the picked nations, branches and advancements and technologies. In Pakistan, the difference between the demand of energy and its supply is increasing every year causing a state of energy crises in the country. Many factors are causing this situation in the country including inadequate energy supply capacity, inefficient utilization of energy resources and a rapid increase in energy demand. Pakistan is facing an energy inefficiency problem both at supply and demand side. On the supply side, issues include low efficiency of power generation plants and high transmission and distribution losses. On the demand side, inefficient use of energy resources is common.Research on the execution of EEMs in compressed air systems was undertaken by Nehler, and Thollander (2018). The research collected data from various users, suppliers, actors and experts involved in the activities of actualizing EEMs. Golove and Eto (2016) assessed the market challenged towards the actualization of energy efficiency. The study focused on the reappraisal of the justification of the public policies to encourage energy efficiency. Extant literature from the study indicated observations on the operation of present energy service markets. However, the study revealed that little of the data/observations has been shared formally through the conceptual framework of transaction cost or market failures. More research into existing findings with regards to the identified concepts in essential to offer a foundation for public policies in the future on energy efficiency, within the identified markets. Improved trials have been made to incorporate the literature in specific terms. Although, a lot of information has been shared, a debate still lingers. In certain situations, identification of some assumptions that can be settled for the sake of the future have been made.

A study on energy efficiency indicators, Phylipsen, (2014), on the practices and potential usage in establishing the policy making in a state. A discussion of different EEMs has been made with the goal of identifying the most appropriate practice in the development and the application of indicators of energy efficiency. Of importance is the ability to conduct cross-state comparisons in a collective approach so as to increase the understanding of issues related to the nation and in particular when high level indicators can be identified. The institutional elements to advance the development of indicators as described could be designed to lower political sensitivities. A research on the energy end-use efficiency, Thollander, Paramonova, Cornelis, Kimura and Navarro (2015). The globalization of different industrial sectors increases the potential for advancing energy efficiency globally. Integrating the technical standards for goods manufactured is an opportunity to reduce the energy efficient products costs through the economies of scale. To discourage energyinefficient products importation, NGOs and government institutions ought to put into consideration the negotiations of efficiency standards for mass-produced goods and appliances imported from other countries. In Hungary and Bangladesh, imported vehicle ought not to be more than 5-6 years old. The same standards can be applied for the importation of energy intensive plants and appliances. In his research paper on the challenges and drivers in the application of energy savings measures for SMEs, Meath, C., Linnenluecke, M., \& Griffiths, A. (2016). indicated that as the long-term potential for energy efficiency lowers the demand for useful energy and the following energy conversion levels, future policy of energy around the world and at the international level has to widen the scope from the supply of energy to energy services. Such a policy may be demanding in establishing a target group and technology specific bundles of policy measures. However, the accomplishment of the process of the new policy is effective from a social, economic and environmental point of view. On the paper on private sector engagement and coordination framework, concluded, Kenya (2019), essentially, awareness initiatives are aimed at the technical staff; the plant managers, engineers, and maintenance staff and in other circumstances the management team including the directors and CEOs do not have a hold of the understanding of the benefits of conducting energy and resource efficiency activities. This leads to the challenge of inadequate management support, allocation of the budget, and time allocation for such activities.

A research on Competitive cities and climate change Kamal-Chaoui and Robert (2018), and concluded that the proposed green growth concept will have to overcome challenges such as limited awareness, poor communication amongst industries, trust, and ability to co-finance for the proposed GCF grant among others. The proposed project should be seen as part of easing the art of doing business in Kenya. There is need to incorporate media as a key stakeholder in simplifying and disseminating the green message.

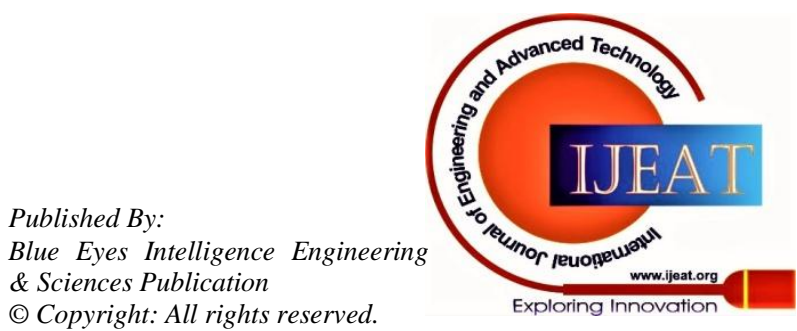


Schwarz (2014) in his paper on; Promoting energy efficiency in buildings concluded that the volatility of the price of energy, uncertainties in supply and environmental issues are driving many states to consider alternatives of energy including energy efficiency and renewable energy that are affordable energy services and can improve energy reliability and security while at the same time ensuring environmental sustainability. The potential of energy efficiency of developing nations remains untapped.

\section{Barriers to Implementation of Energy Efficiency Projects}

A research on identifying the challenges faced in energy efficient project implementation in buildings energy performance contracting and California PACE (Property Assessed Clean Energy) commercial pilot program Buonicore Partners (2014), and concluded that in the current economic and regulatory climate, energy performance contracting allows building owners to implement energy efficiency projects in a way that minimizes financial risk and provides significant short- and long-term financial and environmental benefits. Commercial building owners in California will find that (Energy performance contracting) EPC and the PACE program together present an especially attractive opportunity for financing energy efficiency retrofits. Meath, Linnenluecke and Griffiths (2016), as well investigated the drivers and challenges to the reception of energy savings measures by SMEs and found that there is an unmistakable distinction in what inspires SMEs to turn to be more energy efficient and what restricts their capacity to do as such. Almost twice as the drivers were recognized as challenges and a few organizations encountered various obstructions. While a significant part of existing literature backs the contention that SMEs experience challenges to effectively executing EE due to inadequate resources, new bits of knowledge acquired from our contextual investigation indicate the significance of driving variables, which to date have been underrepresented in the writing. The large number of motivators proposes that SME proprietors are thinking about the positive results and not simply restricting elements. Some SMEs possibly want to change their business activities by partaking in the program. An examination on appropriation of EEM in SMEs (Fleiter, Schleich and Ravivanpong 2014), - This exact investigation depended on energy audit information and concluded that abstract components are derived by means of factor assessment from a large set of singular items and incorporate self-surveyed hindrances to EE reflecting absence of capital, absence of transactional costs, profitability, specialized skills, and the audit quality. The goal factors considered incorporate investment costs, the landowner occupant issue and the utilization of compensation time. Moreover, control factors are added for the econometric analysis to represent the impacts of firmexplicit elements like energy-management, intensity, past EE and the size of the firm. Amankwah-Amoah, (2015), did an investigation on energy efficiency with respect to strategies, public awareness, opportunities and challenges in Kenya and drew the conclusion that the contry has made strides in supporting initiatives on energy efficiency. At a policy level, the Kenyan government has put in place regulatory frameworks and policies with the goal of promoting EEMs in the state. Moreover both state and nonstate actors including development institutions and the private industry have been in support of different initiatives that promote practices of energy efficiency. However, the study acknowledged that there still remains room for more efforts with regards to ensuring that the current regulatory frameworks and policies integrate all the energy efficiency aspects, build personnel capacities and develop energy efficiency infrastructure so as to keep up with the energy demand as stipulated in figure 1.8 below.

\section{Projected Growth in Demand}

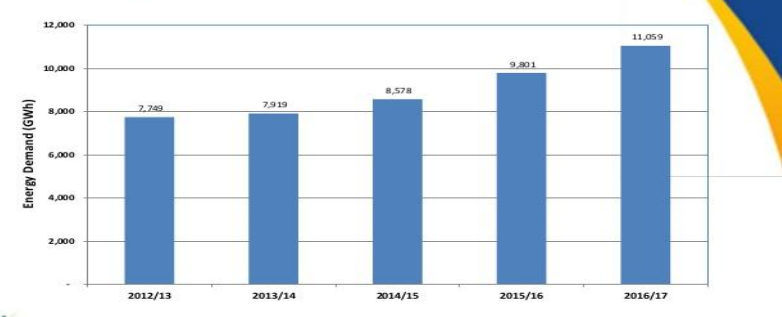

Figure 1.8: Energy demand in Kenya

\section{CONCLUSION}

The aim of the paper was to assess the implementation of EEMs, the achieved savings and the challenges faced in different institutions within the hospitality sector in Kenya. According to the study, the relationship between energy efficiency and conservation within the hospitality sector in Kenya has been characterized with high prices of energy, supply insecurity, health and environmental impacts and the depletion of sources of energy. The government in collaboration with other different partnerships has conducted some initiatives related to energy efficiency and conservation with the goal of solving the challenge of wastage of energy and assess the demand of energy country wide. Currently, the energy demand is matched by the generated energy, however, if all projects in the infrastructure sector are to be considered, a power shortage would be experienced. Therefore, it is imperative for the energy sector to keep up its emphasis on energy efficiency within this period of time where infrastructural projects are slow so as to instill the culture of energy efficiency to ensure the sustainability of the environment. The annual consumption of energy within the hospitality sector has risen over the previous decade as was illustrated in figure 1.4. With regards to the energy loss annually in the hospitality sector, the collected data reealed that variations in energy loss over the last decade has been recorded with 2012 recording the highest loss while 2019 recorded the lowest loss as is evident in figure 1.3. From the reviewed studies, a number of research gaps were identified. The studies did not reveal the challenges faced in the implementation of energy efficiency measures. Most studies only highlighted the implementation concepts.

Published By:

Blue Eyes Intelligence Engineering 


\section{Assessment of Implementation of Energy Efficiency Measures, Savings Achieved and Barriers to Implementation at Various Firms in the Hospitality Industry in Kenya}

On the other hand, the studies did not bring out the relationship among EEMs implementation, achieved savings and challenges faced during implementation, hence presents a research gap.

\section{REFERENCES}

1. Africa, P. (2015). Development of Kenya's Power Sector 20152020. Power Africa: Nairobi, Kenya.

2. Allee, J. M. (2014). Rational inattention and energy efficiency. The Journal of Law and Economics, 57(3), 781-820.

3. Al-Qawasmi, A. R., Abokhalil, A., Daoud, O. R., \& Abu-Isbeih, I. N. (2018). Energy Efficiency Management System Using WSAN:

4. Amankwah-Amoah, J. (2015). Solar energy in sub-Saharan Africa: The challenges and opportunities of technological leapfrogging. Thunderbird International Business Review, 57(1), 1531.

5. Ayyappan, G. S., Raghavan, M. R., Poonthalir, R., Srinivas, K., \& Babu, B. R. (2019). Design and Development of iLON Smart Server Based Remote Monitoring System for Induction Motors. Internationa Journal of Electrical and Information Engineering, 13(11), 710-720.

6. Bishop, R., \& Economy, N. C. (2015). Raising energy efficiency standards to the global best. New Climate Economy.

7. Boampong, R., \& Phillips, M. A. (2016). Renewable energy incentives in Kenya: Feed-in-tariffs and Rural Expansion. University of Florida: Gainesville, FL, USA

8. Brent, A. (2016). Unlocking the potential of energy efficiency and renewable energy. Greening the South African Economy: Scoping the issues, challenges and opportunities.

9. Brown, P., \& Sherriff, G. A. (2014). Research to assess the barriers and drivers to energy efficiency in small and medium sized enterprises.

10. Buonicore Partners, L. L. C. (2014). Energy Efficiency Retrofit Financing Options for the Commercial Real Estate Market.

11. Cagno, E., \& Trianni, A. (2014). Evaluating the barriers to specific industrial energy efficiency measures: an exploratory study in small and medium-sized enterprises. Journal of Cleaner Production, 82, 7083.

12. Cagno, E., Worrell, E., Trianni, A., \& Pugliese, G. (2014). Dealing with barriers to industrial energy efficiency: an innovative taxonomy. In ECEEE Industrial Summer Study (pp. 1-14).

13. Cattaneo, C. (2019). Internal and external barriers to energy efficiency: which role for policy interventions. Energy efficiency, 12(5), 1293-1311.

14. Cingoski, V., \& Petrevska, B. (2018). Making hotels more energy efficient: the managerial perception. Economic research-Ekonomska istraživanja, 31(1), 87-101.

15. Cingoski, V., \& Petrevska, B. (2018). Making hotels more energy efficient: the managerial perception. Economic research-Ekonomska istraživanja, 31(1), 87-101.

16. Council, W. E. (2016). Energy efficiency policies around the world: review and evaluation. In World Energy Council.

17. DOE, U. (2014). Summary of Gaps and Barriers for Implementing Residential Buildings Energy Efficiency Strategies.

18. Dubey, K., \& Dodonov, A. (2019). Mapping of Existing Technologies to Enhance Energy Efficiency in Buildings in the UNECE Region.

19. Fawkes, S., Oung, K., Thorpe, D., Zhu, X., \& Farrell, T. C. (2016) Best practices and case studies for industrial energy efficiency improvement: an introduction for policy makers.

20. Figueroa, A. R. (2016). Efficient lighting uptake among the urban poor: evidence from a Kenyan informal settlement. Environment and Urbanization, 28(2), 535-552.

21. Fleiter, T., Schleich, J., \& Ravivanpong, P. (2014). Adoption of energy-efficiency measures in SMEs-An empirical analysis based on energy audit data from Germany. Energy Policy, 51, 863-875.

22. Fylan, F., Glew, D., Smith, M., Johnston, D., Brooke-Peat, M., MilesShenton, D \& Gorse, C. (2016).

23. Gachau, K. N. (2017). Identifying Energy Saving Opportunities in a Commercial Building in Nairobi: a Case Study of Equatorial Fidelity Centre in Westlands Nairobi (Doctoral dissertation, University of Nairobi).

24. Gachuri, A. K. K. (2017). Barriers And Driving Forces For Industrial

25. Gerarden, T. D., Newell, R. G., \& Stavins, R. N. (2017). Assessing the energy-efficiency gap. Journal of Economic Literature, 55(4), $1486-1525$. Investigation of Energy Consumption of Buildings. Energy Efficiency Improvements In Kenya (Master's thesis)

26. Giner-Reichl, I. (2015). Renewable energy in international and regional governance: Propelling development in Africa. Energy Research \& Social Science, 5, 116-119.

27. Golove, W. H., \& Eto, J. H. (2016). Market barriers to energy efficiency: a critical reappraisal of the rationale for public policies to promote energy efficiency (No. LBL-38059). Lawrence Berkeley Lab., CA (United States).

28. Golove, W. H., \& Eto, J. H. (2016). Market barriers to energy efficiency: a critical reappraisal of the rationale for public policies to promote energy efficiency (No. LBL-38059). Lawrence Berkeley Lab., CA (United States).

29. Golubchikov, O., \& Deda, P. (2014). Governance, technology, and equity: An integrated policy framework for energy efficient housing. Energy policy, 41, 733-741

30. Hassett, K. A., \& Metcalf, G. E. (2018). Energy tax credits and residential conservation investment: evidence from panel data. Journal of Public Economics, 57(2), 201-217

31. Heinzle, S. L. (2016). Disclosure of energy operating cost information: a silver bullet for overcoming the energy-efficiency gap? Journal of Consumer Policy, 35(1), 43-64.

32. Henry, Y. K., Chepkilot, R. K., Kalio, A. Reflections on retrofits: Overcoming barriers to energy efficiency among the fuel poor in the United Kingdom. Energy Research \& Social Science, 21, 190-198.

33. Hobman, E. V., Frederiks, E. R., Stenner, K., \& Meikle, S. (2016) Uptake and usage of cost-reflective electricity pricing: in-sights from psychology and behavioural economics. Renewable and Sustainable Energy Reviews, 57,455-467.

34. Hope, A. J., \& Booth, A. (2014). Attitudes and behaviours of private sector landlords towards the energy efficiency of tenanted homes. Energy Policy, 75, 369-378.

35. Iwaro, J., \& Mwasha, A. (2014). A review of building energy regulation and policy for energy conservation in developing countries. Energy Policy, 38(12), 7744-7755.

36. Jacobsen, G. D., \& Kotchen, M. J. (2013). Are building codes effective at saving energy? Evidence from residential billing data in Florida. The Review of Economics and Statistics,95(1), 34-49.

37. Jenne, C. A., \& Cattell, R. K. (2014). Structural change and energy efficiency in industry. Energy Economics, 5(2), 114-123.

38. Kamal-Chaoui, L., \& Robert, A. (2018). Competitive cities and climate change.

39. Karekezi, Kithyoma and Onguru (2016) evaluating anaerobic digester energy generation: opportunities and barriers. Bio-carbon opportunities in eastern \& southern africa, 160

40. Kariuki, D. (2018). Barriers to renewable energy technologies development. Keele University, UK. DOI: dx. doi. org/10.1515/energytoday-2018-2302.

41. Kasae Perris (2014) Energy Efficiency and Operational Performance of Manufacturing Firms in Kenya. Journals in Business \& Management, 2(3), 15-24.

42. KENYA, C. C. A. P. I. (2019). Private sector engagement and coordination framework.

43. Kidere, M. M. (2017). Analytical assessment of port energy efficiency and management a case study of the Kenya Ports Authority.

44. Kidere, M. M. (2017). Analytical assessment of port energy efficiency and management.: a case study of the Kenya Ports Authority.

45. King, J., \& Perry, C. (2017). Smart buildings: Using smart technology to save energy in existing buildings. Amercian Council for an EnergyEfficient Economy.

46. Kiprop, E., Matsui, K., \& Maundu, N. (2019). The Role of Household Consumers in Adopting Renewable Energy Technologies in Kenya. Environments, 6(8), 95

47. Koskimäki, P. L. (2014). Africa could take a leap to energy efficiency: What lessons could Sub-Saharan countries learn from European energy efficiency policy implementation?. Energy for Sustainable Development, 16(2), 189-196.

48. Kotchen, M. J., \& Moore, M. R. (2017). Private provision of environmental public goods: household participation in greenelectricity programs. Journal of Environmental Economics and Management, 53(1), 1-16.

49. Lah, O. (2015). The barriers to low-carbon land-transport and policies to overcome them. European Transport Research Review, 7(1), 5.

50. M., \& Koima, J. K.(2014) Re-Thinking Energy Efficient Technology In Sustaining Competitive Advantage Among Manufacturers In Developing Economies.

Published By:

Blue Eyes Intelligence Engineering 
51. Mallett and Sorrell (2014). Policy options to overcome barriers to industrial energy efficiency in developing countries.

52. Martinaitis, V., Kazakevičius, E., \& Vitkauskas, A. (2017). A twofactor method for appraising building renovation and energy efficiency improvement projects. Energy policy, 35(1), 192-201.

53. McCollum, D. L., Wilson, C., Pettifor, H., Ramea, K., Krey, V., Riahi, K \& Fujisawa, S. (2017). Improving the behavioral realism of global integrated assessment models: An application to consumers' vehicle choices. Transportation Research Part D: Transport and Environment, 55, 322-342.

54. McKerracher, C., \& Torriti, J. (2013). Energy consumption feed-back in perspective: integrating Australian data to meta analyses on inhome displays. Energy Efficiency, 6(2),387-405.

55. Meath, C., Linnenluecke, M., \& Griffiths, A. (2016). Barriers and motivators to the adoption of energy savings measures for small-and medium-sized enterprises (SMEs): the case of the ClimateSmart Business Cluster program. Journal of Cleaner Production, 112, $3597-$ 3604.

56. Meath, C., Linnenluecke, M., \& Griffiths, A. (2016). Barriers and motivators to the adoption of energy savings measures for small-and medium-sized enterprises (SMEs): the case of the ClimateSmart Business Cluster program. Journal of Cleaner Production, 112, 3597 3604.

57. Meshcheryakova, T. (2017). Conceptual provisions of the implementation of energy saving measures in the residential facilities. In MATEC Web of Conferences (Vol. 106, p. 06021). EDP Sciences.

58. Mlambo-Ngcuka, P. (2015). Energy efficiency strategy of the Republic of South Africa. Department of Minerals and Energy, South Africa, 1.

59. MoEP, K. (2016). Development of a Power Generation and Transmission Master Plan, Kenya. Long term plan-Renewable energy. Kenya Ministry of Energy and Petroleum.

60. Mörtberg, U., Goldenberg, R., Kalantari, Z., Kordas, O., Deal, B., Balfors, B., \& Cvetkovic, V. (2017). Integrating ecosystem services in the assessment of urban energy trajectories-A study of the Stockholm Region. Energy policy, 100, 338-349.

61. Mukwaya, N. I., \& Okidi-Lating, P. (2014). Benchmarking Energy Efficiency of Commercial Office Buildings in Kampala.

62. Munene, M. B., Odongo, J. O., \& Nyambane, A. (2019). Energy efficiency in Kenya.

63. Muthuki, J. (2016). Challenging patriarchal structures: Wangari Maathai and the Green Belt movement in Kenya. Agenda, 20(69), 8391.

64. Mutua, J., \& Kimuyu, P. (2015). Household energy conservation in Development Discussion Paper-Resources for the Future (RFF), (1504).

65. Mutua, J., \& Kimuyu, P. (2015). Household energy conservation in Kenya: estimating the drivers and possible savings. Environment for Development Discussion Paper-Resources for the Future (RFF), (1504).

66. Nadeem, F. (2014). Barriers, Drivers and Policy Options For

67. Nadel, S., \& Keating, K. (2016).Engineering estimates vs. impac evaluation results: how do they compare and why? Research Report U915. American Council for an Energy-Efficient Economy

68. Nair, G., Gustavsson, L., \& Mahapatra, K. (2014, November). Barriers to implement energy efficiency investment measures in Swedish co-operative apartment buildings. In World Renewable Energy Congress-Sweden; 8-13 May; 2011; Linköping; Sweden (No. 57, pp. 1110-1117). Linköping University Electronic Press.

69. Ndichu, J., Blohmke, J., Kemp, R., Adeoti, J., \& Obayelu, A. E. (2015). The adoption of energy efficiency measures by firms in Africa: case studies of cassava processing in Nigeria and maize milling in Kenya. Innovation and Development, 5(2), 189-206.

70. Nehler, T., Parra, R., \& Thollander, P. (2018). Implementation of energy efficiency measures in compressed air systems: barriers, drivers and non-energy benefits. Energy Efficiency, 11(5), 1281 1302.

71. Newell, R. G., \& Siikamäki, J. (2014). Nudging energy efficiency behavior: the role of information labels. Journal of the Association of Environmental and Resource Economists,1(4), 555-598.

72. Nkosi, S. B., \& Pretorius, J. H. C. (2017, July). Challenges and Strength of Current Industrial Energy Efficiency Managemen Practices in Steam Industries. In IOP Conference Series: Earth and Environmental Science (Vol. 73, No. 1, p. 012006). IOP Publishing.

73. Nowak, S., Kushler, M., \& Witte, P. (2014, August). Successful Programs. American Council for an Energy-Efficient Economy. Kenya: estimating the drivers and possible savings. Environment for Improving Industrial Energy Efficiency Practices in Combined Gas and Electric Utility Energy Efficiency

74. Ockwell, D., \& Byrne, R. (2016). Sustainable energy for all: Innovation, technology and pro-poor green transformations. Routledge.

75. Okoth, M. W. (2014). Removal of barriers to energy conservation and energy efficiency in small and medium scale enterprises (Tea sub sector) Global Environmental Facility (GEF)/Kenya Association of Manufacturers Nairobi. University of Nairobi.

76. O'Malley, E., Scott, S., \& Sorrell, S. (2014). Barriers to energy efficiency: Evidence from selected sectors.

77. Ottinger, R. (2017). UNEP Handbook for Drafting Laws on Energy Efficiency and Renewable Energy Resources. United Nations Environment Programme, 3.

78. Owiro, D., Poquillon, G., Njonjo, K. S., \& Oduor, C. (2015) Situational analysis of energy industry, policy and strategy for Kenya. Institute of Economic Affairs.

79. Phylipsen, G. J. M. (2014). Energy Efficiency Indicators: Best practice and potential use in developing country policy making. Phylipsen Climate Change Consulting.

80. Poulsen, R. T., \& Sornn-Friese, H. (2015). Achieving energy efficient ship operations under third party management: How do ship management models influence energy efficiency?. Research in transportation business \& management, 17, 41-52.

81. Rantanen, H., Kulmala, H. I., Lönnqvist, A., \& Kujansivu, P. (2007) Performance measurement systems in the Finnish public sector. International Journal of Public Sector Management.

82. Reddy, A. K. (2015). Barriers to improvements in energy efficiency. Energy policy, 19(10), 953-961.

83. Reddy, B. S. (2014). Barriers and drivers to energy efficiency-A new taxonomical approach. Energy Conversion and Management, 74, 403416.

84. Retallack, S., Johnson, A., Brunert, J., Rasoulinezhad, E., \& Taghizadeh-Hesary, F. (2018). Energy efficiency finance programs: Best practices to leverage private green finance (No. 877). ADBI Working Paper Series.

85. Rezessy, S., Dimitrov, K., Urge-Vorsatz, D., \& Baruch, S. (2016) Municipalities and energy efficiency in countries in transition: Review of factors that determine municipal involvement in the markets for energy services and energy efficient equipment, or how to augment the role of municipalities as market players. Energy Policy, 34(2), 223-237.

86. Rosenberg, S. A., \& Winkler, H. (2014). Policy review and analysis: Energy efficiency strategy for the Republic of South Africa. Journal of Energy in Southern Africa, 22(4), 0-0.

87. Sardianou, E. (2018). Barriers to industrial energy efficiency investments in Greece. Journal of Cleaner Production, 16(13), 14161423.

88. Sarkar, A., \& Singh, J. (2014). Financing energy efficiency in developing countries-lessons learned and remaining challenges. Energy Policy, 38(10), 5560-5571.

89. Scheer, J., Durusut, E., \& Foster, S. (2015). Unlocking the Energy Efficiency Opportunity. Sustainable Energy Authority of Ireland (SEAI), Dublin

90. Schleich, J. (2014). Barriers to energy efficiency: A comparison across the German commercial and services sector. Ecological Economics, 68(7), 2150-2159

91. Schleich, J. (2014). Barrier busting in energy efficiency in industry. United Nations Industrial Development Organization.

92. Schleich, J. (2017). The economics of energy efficiency: barriers to profitable investments. EIB papers, 12(2), 82-109.

93. Schlomann, B., Eichhammer, W., Reuter, M., Frölich, C., \& Tariq, S (2015). Energy Efficiency trends and policies in Germany. Report Prepared by Fraunhofer ISI within the Project "ODYSSEE-MURE.

94. Schlomann, B., Eichhammer, W., Reuter, M., Frölich, C., \& Tariq, S (2015). Energy Efficiency trends and policies in Germany. Report Prepared by Fraunhofer ISI within the Project "ODYSSEE-MURE.

95. Schwarz, V. (2014). Promoting energy efficiency in buildings: lessons learned from international experience. United Nations Development Programme, New York, USA.

96. Semboja, H. H. H. (2014). The effects of an increase in energy efficiency on the Kenya economy. Energy Policy, 22(3), 217-225.

97. Semboja, H. H. H. (2014). The effects of an increase in energy efficiency on the Kenya economy. Energy Policy, 22(3), 217-225.

98. Simiyu, E., (2018). Opportunities and barriers to implementing energy efficiency in selected pumping installations in Kenya. Global Environment Facility Facility.

Published By:

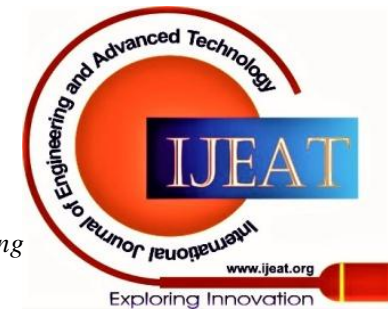




\section{Assessment of Implementation of Energy Efficiency Measures, Savings Achieved and Barriers to Implementation at Various Firms in the Hospitality Industry in Kenya}

99. Stiebert, S. (2014). Kenya's Climate Change Action Plan: Mitigation Chapter 5: Electricity Generation.

100. Szabo, S., Bódis, K., Huld, T., \& Moner-Girona, M. (2014). Energy solutions in rural Africa: mapping electrification costs of distributed solar and diesel generation versus grid extension. Environmental Research Letters, 6(3), 034002.

101. Takagi, T., Sprigings, Z., Nishida, Y., Graham, P., Horie, R., Lawrence, S., \& Miclea, C. P. (2015). Urban efficiency: A global survey of building energy efficiency policies in cities.

102. Tao, J., \& Yu, S. (2011). Implementation of energy efficiency standards of household refrigerator/freezer in China: potential environmental and economic impacts. Applied Energy,88(5), 18901905.

103. Thollander, P., Paramonova, S., Cornelis, E., Kimura, O., Trianni, A., Karlsson, M., ... \& Navarro, J. P. J. (2015). International study on energy end-use data among industrial SMEs (small and medium-sized enterprises) and energy end-use efficiency improvement opportunities. Journal of Cleaner Production, 104, 282-296.

104. Tripanagnostopoulos, Y., \& Tripanagnostopoulou, M. (2017). Energy andaesthetic improvemens for building integration of cost effectivesolar energy systems. In Proc. Int. Conf. CISBAT.

105. UNEP (2017). Overcoming barriers to investing in energy efficiency. United Nations, New York and Geneva.

106. UNEP, D. (2017). Overcoming barriers to investing in energy efficiency. United Nations, New York and Geneva.

107. Ürge-Vorsatz, D., Koeppel, S., \& Mirasgedis, S. (2017). Appraisal of policy instruments for reducing buildings' CO2 emissions. Building Research \& Information, 35(4), 458-477.

108. Vogel, J. A., Lundqvist, P., \& Arias, J. (2015). Categorizing barriers to energy efficiency in buildings. Energy Procedia, 75, 2839-2845.

109. Williams, C. (2014). Gauging Improvements in Urban Building Energy Policy in India.

110. World Health Organization. (2018). Opportunities for transition to clean household energy: application of the household energy assessment rapid tool (HEART): India.

111. Worrell, E. (2014). Barriers to energy efficiency: International case studies on successful barrier removal. Development Policy, statistics and research branch, working paper 14/2011, 1-19.

112. Worrell, E., Laitner, J. A., Ruth, M., \& Finman, H. (2014). Productivity benefits of industrial energy efficiency measures. Energy, 28(11), 1081-1098.

113. Xu, Pengp and Chan (2015). Barriers to implementing energy performance contracting (EPC) mechanism into hotel buildings retrofit in china. In Management and Innovation for a Sustainable Built Environment MISBE 2011, Amsterdam, The Netherlands, June 20-23, 2011. CIB, Working Commissions W55, W65, W89, W112; ENHR and AESP.

114. Yatich, K. H. (2018). Realizing energy management practices as a competitive strategy among manufacturing firms in Kenya: An alternative outlook.

115. Yazdanpanah, M., Komendantova, N., \& Ardestani, R. S. (2015) Governance of energy transition in Iran: Investigating public acceptance and willingness to use renewable energy sources through socio-psychological model. Renewable and Sustainable Energy Reviews, 45, 565-573.

116. Zeng, S. X., Tian, P., \& Tam, C. M. (2017). Overcoming barriers to sustainable implementation of the ISO 9001 system. Managerial Auditing Journal.

117. Zhu, J. Y., Pan, X., \& Zalesny, R. S. (2014). Pretreatment of woody biomass for biofuel production: energy efficiency, technologies, and recalcitrance. Applied microbiology and biotechnology, 87(3), 847857.

\section{AUTHORS PROFILE}

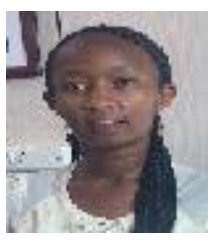

Anne W. Kariuki, Holds a Bachelors in Energy Engineering from Kenyatta University, Kenya. She also has a diploma in Efficient Energy Use and Planning from Life Academy, Sweden and an advocate level on Regulation for Universal Access to Energy from the Florence School of Regulations. She is trained on various topics on energy policy and the energy-water-food nexus. She is a Certified Energy Manager with the Association of Energy Engineers. She is a bronze founding member of the Association of Energy Professionals, Eastern African Chapter; Council of Women in Energy and Environment Leadership (CWEEL) and Global Women's Network for the Energy Transition (GWNET).

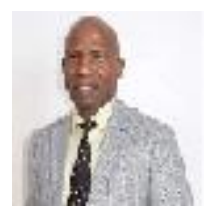

Ernest A. Odhiambo, holds a $\mathrm{PhD}$ in Mechanical Engineering from National Taiwan University of Science \& Technology, MPhil - Mechanical Engineering from Queen Mary University of London, UK. He is currently a lecturer at the University of Nairobi, Kenya. He has vast experience in Fire Protection, Smoke Propagation Egress Simulation for TDB, Nairobi, Fire Protection, Smoke Propagation Simulation for Laico Regency, Nairobi (New Project) Fire Protection, Smoke Propagation, Egress Simulation for Hyatt Place, Nairobi (Complete), Computational Aerodynamic Modelling Vehicle Drag for ISUZU East Africa, Nairobi (Complete) and Numerical (Computational) Optimization of Sony Sugar Company Thermal Plant, Awendo

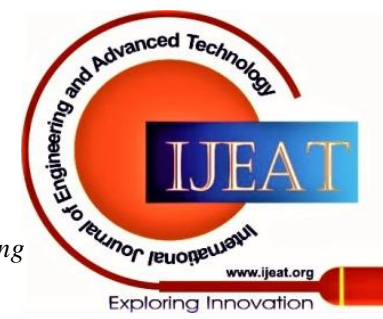

